\title{
A AUDIODESCRIÇÃO NO ENSINO SUPERIOR A DISTÂNCIA.
}

\author{
NITERÓI/RJ JULHO/2018
}

\author{
Luciana Tavares Perdigão - UFF - lucianaperdigao@id.uff.br \\ Neuza Rejane Wille Lima - UFF - rejane_lima@id.uff.br \\ Tipo: Investigação Científica (IC) \\ Natureza: Relatório Final de Pesquisa \\ Categoria: Métodos e Tecnologias \\ Setor Educacional: EDUCAÇÃO SUPERIOR
}

\begin{abstract}
RESUMO
A inclusão do aluno com deficiência visual é ainda uma questão muito incipiente no ensino superior a distância. A legislação garante o acesso desse aluno no ensino público, porém, as universidades não se encontram plenamente preparadas para atender a essas necessidades educacionais. $O$ presente estudo é um recorte da pesquisa de mestrado VENDO COM OUTROS OLHOS - A AUDIODESCRIÇÃO NO ENSINO SUPERIOR A DISTÂNCIA. A pesquisa teve como objetivo implementar a utilização da audiodescrição para a acessibilidade dos recursos imagéticos nos materiais didáticos do curso de Licenciatura em Geografia aos alunos com deficiência visual. $O$ recorte é da etapa de capacitação dos coordenadores e tutores, através do Curso de Introdução a Audiodescrição em EAD desenvolvido e realizado na plataforma Moodle. A capacitação contou com a participação de quatro coordenadores de disciplina, quinze tutores e um aluno com deficiência visual, além de um consultor cego.
\end{abstract}

Palavras-chave: tradução visual, deficiência visual, tecnologia assistiva, material didático, educação a distância.

\section{AGRADECIMENTOS}

AGRADEÇO AO CURSO DE MESTRADO PROFISSIONAL EM DIVERSIDADE E INCLUSÃO DA UFF POR TODOS OS ENSINAMENTOS AO LONGO DESSES DOIS ANOS DE PESQUISA. 


\section{Introdução}

Os estudos sobre acessibilidade me acompanham desde 2012 quando trabalhava com acessibilidade web e lecionava a disciplina com mesmo nome na pós-graduação em mídias do UNI-BH. Desde então foram diversas publicações (PERDIGÃO \& ALVES, 2015; LIMA, DELOU, \& PERDIGÃO, 2016; PERDIGÃO \& LIMA, 2016) até conhecer e me envolver com a audiodescrição no início de 2016 por meio de duas capacitações no Instituto Benjamin Constant, um curso de extensão com o professor Francisco Lima pela UFPE, duas oficinas no Encontro Internacional de Audiodescrição com a profa. Josélia Neves e o Prof. Joel Snyder e atualmente como pós-graduanda do curso de Tradução Audiovisual Acessível - Audiodescrição da UECE. Ao longo dos estudos foram apresentadas diversas publicações de pesquisa (PERDIGÃO, LIMA \& MOREIRA, 2017; PERDIGÃO \& LIMA, 2016; PERDIGÃO \& LIMA, 2017; PERDIGÃO, LIMA \& BAHIA, 2017) bem como apresentação de trabalhos em eventos (I e II Além do Olhar da UFF, III Encontro de Diversidade e Inclusão da UFF, III Encontro Internacional de Audiodescrição, $16^{\circ}$ Ergodesign - Congresso Internacional de Ergonomia e Usabilidade de Interfaces Humano Tecnológica e o CINAHPA 2017 - Congresso Internacional de Ambientes Hipermídia para Aprendizagem). Ministrei a I Oficina de Introdução à Audiodescrição da Escola de Inclusão da UFF - 2017. Desde 2016 faço parte do grupo de pesquisa NDVIS - Núcleo de Desenvolvimento de Produtos e Processos Inclusivos na Perspectiva da Deficiência Visual. A escolha do recorte dessa pesquisa se deu pela minha atuação profissional como designer instrucional do curso de Geografia Cederj UERJ e membro da Comissão de atendimento ao aluno com necessidade educacional especial do Consórcio. Aproveitei essa experiência para desenvolver todas as etapas do curso utilizado como ferramenta desse estudo, bem como as ações de tutoria. Toda a trajetória desta pesquisa está relatada no blog https://vendocomoutrosolhos.wordpress.com/

As primeiras questões deste estudo foram levantadas no ano de 2016 quando foi identificada a presença de um aluno matriculado no curso de Geografia do Consórcio Cederj. De acordo com a Diretoria de pólos do Cederj, no primeiro semestre de 2017, 72 alunos com algum tipo de necessidade educacional especial foram matriculados nos cursos de graduação. Desses, 42 alunos possuíam algum tipo de deficiência visual. De 2015 a 2017 o aumento de matrículas desse perfil de aluno aumentou 31,25\%. A partir desses números foi iniciada uma busca por tecnologias que pudessem atender à demanda desses alunos e a audiodescrição se apresentou como uma alternativa. A audiodescrição é uma tecnologia assistiva baseada na modalidade da tradução audiovisual intersemiótica que permite o acesso à informação, à comunicação, à educação, ao lazer e à cultura através da transformação das imagens em palavras de 
forma clara, concisa, coesa, específica e vívida (Perdigão, 2017). Atualmente, os alunos com deficiência visual do Cederj recebem os materiais didáticos em arquivos digitais adaptados, convertidos para a extensão txt. Essa adaptação atende apenas ao conteúdo textual do material, não abrangendo a acessibilidade das imagens. $O$ aluno precisa contar com a ajuda do tutor e de terceiros para conseguir atingir aos objetivos de aprendizagem de cada disciplina.

O eixo hipotético da pesquisa é que o recurso da audiodescrição possibilita a acessibilidade aos conteúdos imagéticos pelas pessoas com deficiência visual. Quando utilizada nos materiais didáticos, a audiodescrição estabelece um processo de mediação pedagógica favorecendo a autonomia do aluno com deficiência visual no processo de aprendizagem.

\section{Objetivos}

O objetivo da pesquisa foi desenvolver uma Capacitação para os coordenadores de disciplina e tutores terem condições de desenvolver as audiodescrições dos conteúdos imagéticos das suas disciplinas no curso de Geografia do Consórcio Cederj.

\section{Referencial teórico}

A pesquisa foi fundamentada em uma revisão de literatura à luz da inclusão no ensino superior a distância (CAST, 2011; MIANES, 2016 e SÁ, 2015), e no estado da arte da audiodescrição (LIMA, 2011; MOTTA, 2015; SNYDER, 2014).

Embora a conveniência e a flexibilidade da educação a distância sejam vantagens para muitos alunos, para alguns a educação a distância faz toda a diferença entre uma qualidade de vida mais rica e outra mais limitada (MOORE E KEARSLEY, 2007). Enganam-se aqueles que pensam que a aprendizagem a distância é um caminho mais fácil para estudar. Ainda que mais flexível e mais conveniente, não é mais fácil, pois implica numa aprendizagem ativa ao contrário dos antigos modelos de ensino presencial onde 0 aluno fica passivamente esperando que 0 professor entregue 0 seu conhecimento. EAD é exatamente o contrário disso. É para pessoas que sabem o que querem e estejam dispostas a se empenhar, com inteligência e determinação, para construir ativamente o novo conhecimento (LITTO, 2010). 
O Centro de Tecnologia Especial Aplicada (Center for Applied Special Technology CAST), criado em 1984 com o objetivo de explorar as formas de uso das novas tecnologias para promover melhores experiências educacionais para pessoas com deficiência, foi o responsável pela criação do conceito de Design Universal para a Aprendizagem - DUA (Universal Design for Learning - UDL). Trata-se de um conjunto de princípios e de estratégias relacionadas com o desenvolvimento curricular (CAST, 2014) buscando reduzir as barreiras ao ensino e à aprendizagem. Dispõe da flexibilidade da tecnologia digital para projetar ambientes de aprendizagem que ofereçam opções para diversas necessidades de aprendizado.O UDL aborda a necessidade de tornar a educação mais sensível às diferenças dos aprendizes garantindo que seja mais distributiva e efetiva (MEYER et. al., 2014).

O crescente campo do Design Universal para a Aprendizagem (UDL) necessita de pesquisas e resultados aplicados consistentes e um conjunto mais amplo de métodos e ferramentas inovadoras para implementação em larga escala. A inclusão no ensino superior a distância converge para este campo e pode trazer bons resultados para serem difundidos e replicados. O designer instrucional tem papel fundamental na compreensão e na implantação dessas diretrizes. Segundo MEYER et. al. (2014) é importante reforçar que UDL não se trata de tecnologia e sim de pedagogia. A audiodescrição pode ser considerada como um dos recursos utilizados no Design Universal para a Aprendizagem.

Apesar da linguagem parecer uma capacidade nata dos professores, muitos ainda desconhecem que este pode ser um caminho para tornar as suas aulas mais acessíveis. Para isso eles precisam conhecer e estar capacitados para fazer audiodescrição além de incentivar seus alunos a participar dessa construção. Segundo Motta (2016) é preciso preparar docentes para que sejam capazes de fazer a leitura desse mundo caoticamente imagético e de ensinar seus alunos a fazê-lo. A audiodescrição das imagens no contexto didático vai além da inclusão do aluno cego. Para a autora, aprender a ler imagens pode colaborar para a formação de alunos mais críticos, mais capazes de compreender os aspectos culturais, históricos e sociais contidos nas informações visuais. (MOTTA, 2016, p. 15) A proposta de uma audiodescrição com fins didáticos, além de inclusiva é inovadora, tornando-se um instrumento à disposição do professor (ZEHETMEYR et. al., 2015). De acordo com os autores, a audiodescrição didática ultrapassa o limite da ferramenta de intermediação entre o visual e o textual e passa a ser objeto de ensino nas mãos do professor inclusivo. As imagens estáticas como fotos, desenhos, pinturas, cartuns, tirinhas, gráficos, mapas e outras; e as imagens dinâmicas como: vídeos e animações são utilizadas não somente para ilustrar, chamar a atenção e tornar as apresentações mais atraentes, mas também para enfatizar 
aquilo que os professores estão apresentando, complementar o entendimento e torná-lo mais facilmente compreendido ou assimilado. Todos esses recursos visuais têm o seu significado e não são escolhidos aleatoriamente: daí a necessidade de traduzi-los de um meio para outro, transformando as imagens em palavras. (MOTTA \& ROMEU FILHO, 2010.)

\section{Procedimentos metodológicos}

O presente estudo teve como base a pesquisa qualitativa, por meio de uma pesquisaação que aconteceu através do desenvolvimento e aplicação da Capacitação em Audiodescrição para os coordenadores de disciplina e tutores através da Plataforma Moodle Cederj, com a participação do aluno com deficiência visual.

\subsection{Produção da capacitação}

A partir do conhecimento inicial adquirido em outros cursos de formação, foi elaborada uma matriz de design instrucional para a Capacitação em audiodescrição para os Coordenadores de Disciplina e Tutores do curso de Graduação em Geografia do Cederj. A matriz contém a ementa e um mapa de atividades que descreve um detalhamento de cada unidade de aprendizagem contemplando: objetivos, estruturação, tema, carga horária, atividades teóricas e práticas, ferramentas e recursos necessários para a realização dos estudos.

Em seguida foram realizadas etapas de desenvolvimento da capacitação: solicitação à equipe de suporte para criação da sala na Plataforma Moodle Cederj; criação da identidade visual da pesquisa que serviu de base para o projeto gráfico do curso e da sala de aula virtual; organização da estrutura da sala de acordo com a ementa e o mapa de atividades; produção e edição do vídeo de abertura; criação dos conteúdos das aulas; solicitação da autorização de uso de imagens de terceiros; elaboração das atividades online.

A capacitação foi planejada com uma carga horária de 30 horas aula distribuídas em 6 semanas de aprendizagem com momentos síncronos e assíncronos. Teve como objetivo instruir os tutores e coordenadores de disciplina para as boas práticas na elaboração de audiodescrição de imagens estáticas das disciplinas do curso de graduação em Geografia Cederj / UERJ. Para a revisão dos roteiros a serem elaborados ao longo do curso foi contratado um consultor cego que, por ser um membro de fora da Fundação Cecierj não teve acesso à plataforma. Neste caso, a pesquisadora teve que mediar as ações entre os participantes e o consultor. O procedimento adotado foi de comum 
acordo entre a pesquisadora e o consultor, que ora se comunicavam por e-mail, ora se comunicavam via whatsapp. Por vezes o audio do whatsapp era mais dinâmico, mas como a intenção da pesquisadora era registrar os principais erros e problemas de um produto audiodescrito, fez-se necessário priorizar o uso do e-mail para facilitar o registro da pesquisa.

\subsection{Realização da capacitação}

O curso teve início no dia 26 de junho de 2017 com a chamada "Aula 0" onde os participantes puderam conhecer a professora e pesquisadora através de uma apresentação em vídeo. Além das boas vindas, a aula 0 teve como objetivo apresentar a ementa, o plano de aula e o guia de estudos e a equipe. Os participantes tiveram que preencher e assinar o TCLE, responder a uma enquete sobre o melhor dia e horário para realização das atividades síncronas e responder ao questionário de expectativas. Nessa semana também foi disponibilizada a aula 1 que teve como tema o Contexto histórico e aspectos legais da audiodescrição. Um dos materiais de estudo foi o texto "A Correta Grafia de Áudio-descrição" do Prof. Francisco Lima, uma das referências desta pesquisa. Apesar de todo o embasamento teórico apresentado pelo autor no artigo, durante o período do curso, o dicionário Michaellis lançou o verbete "audiodescrição" sem hífen. Nesse momento a pesquisadora optou por utilizar a grafia do dicionário por conta da popularização que deverá ser dada ao termo assim escrito. Além das leituras dos conteúdos os participantes tiveram que participar do fórum de apresentação e fazer uma análise inicial do caderno didático das disciplinas em que atuam, enumerando os conteúdos imagéticos presentes.

A segunda semana de aula teve como tema as Normas técnicas vigentes e principais erros cometidos na audiodescrição. Na abertura dessa aula foi utilizada a imagem de uma postagem da Coca-cola no Facebook utilizando a hashtag \#pracegover. Essa hashtag foi criada em 2012 por Patrícia Silva de Jesus, (Patrícia Braille), com o objetivo de transformar o Facebook em um espaço virtual mais acessível. Por ser uma rede social, as postagens associadas a essa hashtag, normalmente são publicadas sem seguir as diretrizes básicas de audiodescrição, que foram apresentadas aos participantes do curso através do material desenvolvido pela Audio Description Coalition e traduzido pelos Associados da Inclusão. Os participantes tiveram como atividades, um fórum onde eles deveriam discutir quais os erros cometidos na postagem e selecionar uma das imagens elencadas na aula anterior para fazerem a primeira audiodescrição. $O$ aluno com deficiência visual foi incentivado a atuar em parceria com os demais participantes na análise das produções audiodescritas. 
A terceira semana de aula tratou do papel do consultor, que, além do incremento para a qualidade do produto audiodescrito, exerce também um papel político no protagonismo dos processos inclusivos. A aula teve como apresentação um vídeo de Felipe Mianes, consultor cego, e um dos referenciais desta pesquisa. Um dos conteúdos desta aula é um artigo produzido e publicado pela própria pesquisadora, onde apresenta as diferenças da audiodescrição realizada por um amador, por um profissional e por um profissional com auxílio do consultor (PERDIGÃO, 2016). Nesta aula os participantes tiveram uma atividade de glossário de desenvolvimento de conceitos e também uma atividade colaborativa de análise das audiodescrições produzidas, tanto pelo aluno com deficiência visual e pelos demais colegas.

A quarta semana de aula abordou especificamente a audiodescrição de imagens estáticas, trazendo como objetivos: conhecer as possibilidades de aplicação de aulas inclusivas através da audiodescrição; analisar os exemplos audiodescrições de paisagens; confrontar os resultados analisados com o pilar "Descreva o que você vê". Apresentou uma atividade colaborativa para os participantes dialogarem sobre as imagens que eles consideram um desafio para audiodescrever, além da atividade individual semanal de audiodescrever uma das imagens selecionadas na aula 1. Todas as atividades individuais foram enviadas por e-mail para o consultor cego analisar. A cada aula o aluno com deficiência visual foi incentivado a participar das atividades seja como colaborador, seja como consultor das atividades realizadas pelos participantes.

A aula 5 teve como tema a audiodescrição didática e trouxe um conteúdo sobre a utilização da audiodescrição nos cadernos didáticos e o reflexo disso na aprendizagem do aluno com deficiência visual. Apresentou também um quadro sobre as categorias para análise de imagens com base nos estudos do Prof. Francisco Lima, que trata-se de uma ferramenta muito útil para orientação no desenvolvimento da audiodescrição. Nas atividades, os participantes foram incentivados a construir colaborativamente um quadro de categorias de descrição de imagens específicas da Geografia.

A última semana do curso teve uma atividade síncrona agendada de acordo com a enquete realizada no início da capacitação. Realizada através da ferramenta Adobe Connect disponível na própria plataforma Moodle Cederj, foi importante para o fechamento das atividades, esclarecimento de dúvidas e encerramento. Apresentou também algumas das produções realizadas pelos participantes gravadas através de sintetizadores de tela e disponibilizados via arquivos de áudio, para os participantes terem uma noção de como o aluno recebe aquele conteúdo para estudo. Como última atividade, os participantes tiveram que responder a um questionário para análise Colles de receptividade em relação ao curso. 


\section{Apresentação e discussão dos resultados}

Ao longo de 4 dias foram preenchidas as 20 inscrições disponibilizadas. O limite foi determinado pela pesquisadora por causa do custo com a consultoria. Dos 20 participantes inscritos, 4 são coordenadores de disciplina, 4 são tutores a distância e 11 são tutores presencias, além do aluno com deficiência visual. Durante as 6 semanas do curso, todos os 4 coordenadores de disciplina evadiram do curso. Dentre as justificativas, o desligamento do consórcio, a falta de tempo e a situação política e financeira na UERJ foram as principais razões. Entre os 15 tutores inscritos, 3 evadiram do curso sem justificativas e 4 não conseguiram realizar atividades suficientes para alcançar a média de $65 \%$ do curso. 8 tutores conseguiram concluir o curso com sucesso sendo que 5 deles com uma média de aproveitamento acima de $80 \%$.

Os frutos dessa capacitação foram as audiodescrições dos conteúdos imagéticos das disciplinas participantes da Geografia que teve a validação do consultor e do aluno cego. Ao todo foram 66 audiodescrições produzidas e avaliadas sendo que nem todas foram finalizadas pelos participantes. Segundo Vergara-Nunes (2016) há dois agentes humanos importantes envolvidos nesse processo de conhecer com o apoio da audiodescrição: por um lado, o usuário, que se baseia em todas as suas vivências e conhecimentos prévios para apreender o conteúdo audiodescrito e assimilar de forma mais precisa a imagem audiodescrita; por outro lado, está o audiodescritor, mediador entre a imagem e o usuário e o trabalho que ele realiza. A ementa do curso foi bem recebida pelos participantes de uma forma geral, mas alguns conteúdos, atividades e dinâmicas do curso terão que ser alteradas para o produto final. Pela pesquisa-ação é possível estudar dinamicamente os problemas, decisões, ações, negociações, conflitos e tomadas de consciência que ocorrem entre os agentes durante o processo de transformação da situação. (THIOLLENT, 2008, p. 19.)

\section{Conclusões}

A pesquisa atendeu ao objetivo principal de construir uma metodologia para implementar a utilização da audiodescrição dos recursos imagéticos nos materiais didáticos do curso de Licenciatura em Geografia para a acessibilidade aos alunos com deficiência visual. Apresentou como produto de pesquisa um Curso de Introdução a Audiodescrição em EAD e um Guia instrucional de diretrizes para utilização da audiodescrição em materiais 
didáticos no ensino superior, que poderá ser aplicado em outros cursos do Consórcio e utilizado por outras instituições de ensino superior.

\section{Referências}

CAST, Center for Applied Special Technology. Universal Design for learning guidelines version 2.0. Wakefield, MA: 2011.

LIMA, Francisco J.; GUEDES, Lívia C.; GUEDES, Marcelo C. Áudio-descrição: orientações para uma prática sem barreiras atitudinais, 2013. Disponível em: $<$ http://www.apabb.org.br/admin/files/Artigos/rbtv.pdf>. Acesso em setembro de 2016

LITTO, Fredric M. Aprendizagem a distância. São Paulo: Imprensa Oficial do Estado de São Paulo, 2010. Disponível em: $<$ http://www.abed.org.br/arquivos/APRENDIZAGEM_A_DISTANCIA.pdf>. Acesso em: 01 de novembro de 2017.

MIANES, Felipe Leão. Consultoria em audiodescrição: alguns caminhos e possibilidades in CARPES, Daiana Stockey (org.). Audiodescrição: práticas e reflexões - Santa Cruz do Sul: Catarse, 2016. Cap. 1, p.10-21.

MICHAELLIS, Dicionário. Editora Melhoramentos Ltda, 2017. Disponível em: $<$ http://michaelis.uol.com.br/moderno-portugues/busca/portugues-brasileiro $>$. Acesso em novembro de 2017.

MOORE, Michael; KEARSLEY, Greg. A educação a distância: uma visão integrada. Trad. Roberto Galman. São Paulo: Thomson Learning, 2007.

MOTTA, Lívia Maria Villela. A audiodescrição na escola: abrindo caminhos para leitura de mundo. São Paulo: Pontes, 2016.

PERDIGÃO, Luciana Tavares; LIMA, Neuza Rejane Wille; MOREIRA, Cristiano Marins. $O$ audioguia do Museu do Amanhã: um paralelo entre a experiência de um cego e um vidente. In: $3^{\circ}$ Encontro (Inter)nacional de Audiodescrição Recife, 2017. Disponível em $<$ https://encontrointernacionalad.files.wordpress.com/2017/03/o-audioguia-do-museu-doamanhc3a3.pdf>. Acesso em julho de 2017. 
PERDIGÃO, Luciana Tavares; LIMA, Neuza Rejane Wille Lima. Imagens que Falam: a áudio-descrição em materiais didáticos. In: Lima Neuza Rejane Wille, Cristina Maria Carvalho Delou. (Org.). Pontos de vista em diversidade e inclusão. 1ed.Niterói: PerSe,, 2016, v. 1, p. 56-62.

PERDIGÃO, Luciana Tavares; LIMA, Neuza Rejane Wille Lima. Acessibilidade digital e o mundo real: uma análise sobre audioguia do museu do amanhã. In: $16^{\circ}$ Ergodesign Congresso Internacional de Ergonomia e Usabilidade de Interfaces Humano Tecnológica, 2017, Santa Catarina. Blucher Design Proceedings. São Paulo: Editora Blucher, 2017. p. 640.

SÁ, Elizabet Dias de Sá. A consultoria na prática da audiodescrição: a perspectiva dos consultores com deficiência visual. Juiz de Fora, MG, 2015. 49p. Monografia (pósgraduação) - Universidade Federal de Juiz de Fora.

SASSAKI, Romeu Kazumi. Por que o nome "Tecnologia Assistiva"? In Assistiva: tecnologia e educação. Porto Alegre, 1996. Disponível em: . Acesso em outubro de 2016.

SNYDER, Joel. The Visual Made Verbal: A Comprehensive Training Manual and Guide to the History and Applications of Audio Description. American Council of the Blind, Arlignton, VA, 2014.

THIOLLENT, M. Metodologia da pesquisa-ação. 16a ed. São Paulo, Cortez. 132 p. 2008.

VERGARA-NUNES, Elton. Audiodescrição didática. - Florianópolis, SC, 2016. 412p. Tese (doutorado) - Universidade Federal de Santa Catarina. Disponível em: $<$ http://btd.egc.ufsc.br/wp-content/uploads/2016/05/Elton-Vergara-Nunes.pdf $>$. Acesso em agosto de 2016. 